\title{
MECHANICAL STATE OF MULTI-STORY STRUCTURES INDUCED BY WIND ACTION
}

\author{
F. Blaga a, *, I. Ladar a \\ a Technical University of Cluj-Napoca, Faculty of Civil Engineering, Constantin Daicoviciu 15, Cluj-Napoca, Romania, \\ Florin.BLAGA@mecon.utcluj.ro
}

Received: 16.01.2017 / Accepted: 20.01.2017 / Revised: 06.05.2017 / Available online: 31.05.2017

DOI: 10.1515/jaes-2017-0005

KEY WORDS: dynamic analysis, multi-storey structures, wind action, energy state

\begin{abstract}
Objective of the present study is to define the dynamic mechanical response of multi-story structures acted upon by wind. Structural response is associated to the dynamically applied wind and is approached by considering its three components: static, kinematic and energy states. Proposed objective is achieved by structural dynamic analyses performed on multi-story steel structures in elastic domain. The dynamic model is the multi-degree of freedom system associated to lateral story level displacements. Dynamic forces are computed from recorded velocities of wind through a simple velocity - pressure - force transform. The matriceal differential equation of wind induced vibratory state is dealt with by both, direct integration and modal decomposition. The three components of the mechanical state are expressed via base shear force - the static state, lateral story-level displacements - the kinematic state and wind induced energy - the energy state. Modal decomposition of the dynamic response allows for immediate computation of modal contribution to the total wind response. Computed values of the parameters are numerically and graphically presented and commented. Relevant conclusions are inferred.
\end{abstract}

\section{INTRODUCTION}

Structural design, in most of its stages, is based on standard code provisions regarding the loads acting on structures as a whole or on its components. Wind action on Civil Engineering structures is such an example that involves a large amount of mathematical considerations aimed at substituting the structural response to dynamic wind by a static response. In spite of being difficult to be dealt with via codes and standards, the wind action is, still, largely applied as an equivalent static load. Indeed, the classical approach to wind action of multistory structures consists of substitution of dynamic wind action by statically applied lateral floor forces (EN 1991-1-4, 2005), (CR 1-1-4, 2012), (Holmes, 2015), (Simiu, 1996). Static analysis of multistory structures to wind action considers the wind as acting along two orthogonal directions of the structure: the along or primary translational direction and across wind. The along wind is, in its turn, decomposed into three velocity components, Figure 1: the mean or static component $\mathrm{Vm}(\mathrm{t})$, the background fluctuating component $\mathrm{v}(\mathrm{t})$ and resonant $\mathrm{v}_{\mathrm{r}}(\mathrm{t})$, where $\mathrm{z}$ is the height above ground level. Structural response to wind is - in its turn - computed as the sum of three above components (Holmes, 2015), (Chen, 2005). In the case of structures with high frequency of vibration, resonant component is small and can be neglected. As a consequence of neglecting resonant component, the wind action is - practically made up of the two popular components: the mean or static component $\mathrm{v}_{\mathrm{m}}(\mathrm{z}, \mathrm{t})$ and the background fluctuating component $\mathrm{v}(\mathrm{z}, \mathrm{t})$, Figure 2. Regarding the $3^{\text {rd }}$ resonant component, its distribution is dependent on the inertial properties of the structure and on the number of natural modes of vibration considered (Chen, 2005), (Holmes, 2012). Generally, the first natural mode is the only one taken into account, but in the case of special structural geometries, the influence of higher natural modes of vibration is relevant (Tamura, 2012). Nevertheless, the wind load distribution in its resonant component leads to an acceptable accuracy taking into account that the structural response due to fluctuating part is rapidly balanced by the damping structural capacity (Holmes, 2012).

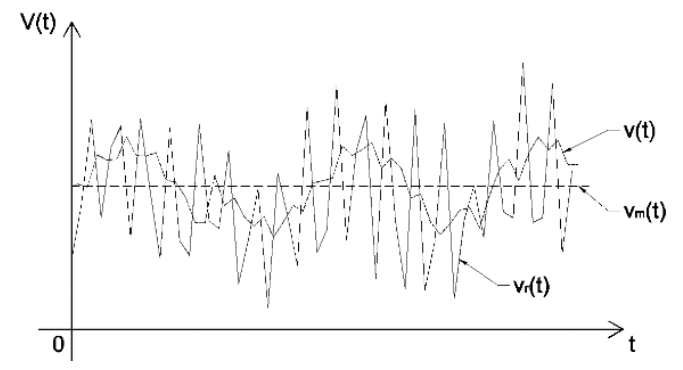

Figure 1. The three components of wind action

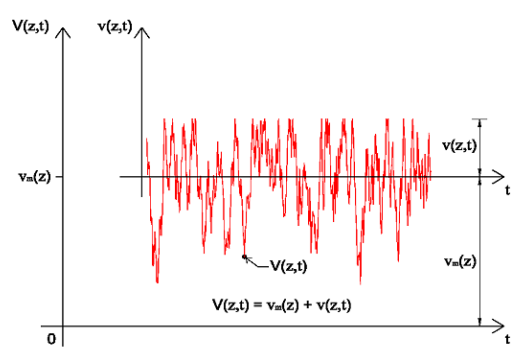

Figure 2. The quasi static two wind components

Whatever are the wind components are taken into account, the structural analysis is, mainly, conducted in a static procedure that has to ensure the largest wind effects in terms of SLU and SLS specificities. Usually, the wind load is considered together other loading components such as dead loads, live loads, snow load

\footnotetext{
* Corresponding author: Florin Blaga, e-mail: Florin.BLAGA@mecon.utcluj.ro
} 
according to standard rules of load combinations (CR0, 2012). This provision of combining wind action with other statically applied loads is, may be, responsible for the static approach to wind action - the so called ESWL approach to wind action. After the first proposal of substituting the dynamicity of wind action by equivalent statically applied loads via Gust Loading Factor GLF (Davenport, 1967), several other studies have refined this static technique (Simiu, 1976), (Solari, 1982), (Holmes, 2002), (Kasperski, 1992), (Davenport, 1995), (Piccardo, 2000), (Piccardo, 2002). Nevertheless, the GLF technique is, still, generally accepted by code design provisions in the structural design in its initial form. In short, the dynamicity of wind action is substituted by a set of parameters while the statically applied wind forces are computed on the base of velocity of wind (EN 1991-1-4, 2005). Nevertheless there are aspects associated to dynamic action that cannot be statically approached, as there are several energy components induced by vibratory motion generated by wind. Also, such phenomenon as damping intimately connected to structural vibrations can only be studied considering dynamic wind action. Damping - in its both forms, inherent and added - has become a modern means in mitigation of seismic response (Puthanpurayil, 2011), (Ladar, 2013). No static approach to any structural vibratory motion induced by natural phenomena may be associated to damping. The context of energy state associated to wind action on multistory steel structures is the main objective of the present contribution. The study proposes a dynamic approach to wind response by defining an energy state that enlarges the classical mechanical state made up of its traditional static and kinematic components. To connect the popular analysis of multistory structures under wind action, wind response is expressed via both, the traditional static and kinematic parameters (base shear, lateral floor displacements) and via proposed energy state.

\section{STRUCTURES AND ACTIONS}

Analyzed structures are a set of planar multistory steel frames of medium height. Presented numerical results are associated to a 12 story, 5 bays reference steel structure, Figure 3 , and its braced version, Figure 4. Reference structure has been designed according to Romanian code provisions and observes SLU conditions while its braced version observes both, SLU and SLS conditions. Time- history analyses require a damping state to be provided. A usual $2 \%$ of ratio of critical damping has been considered as inherent liner viscous damping. Considered actions are a set of two wind type loads in the form of concentrated story level lateral forces. Dynamical set of lateral wind forces $\mathrm{F}_{\mathrm{i}}(\mathrm{t})$ $(\mathrm{i}=1, \mathrm{n})$ are computed from wind pressure that, in its turn, is the result of a mathematical processing of recorded wind velocity (Barszcz, 2012), (Blaga, 2016). Two computed speedo-grams V1, Figure 5 and V2, Figure 6 - based on reference velocity of $27.0 \mathrm{~m} / \mathrm{s}$ - are applied on the two structures. A duration of 600 sec. of wind action has been considered. The two wind actions are, basically, different of each other: wind action V1, Figure. 5, emphasizes a strong time variation between quasi constant speed limits while, wind action V2, Figure. 6, emphasizes continuous descend of its velocity. The floor level applied loads $F(z, t)$ are computed as the sum of the two components, Figure 7: pressure $\mathrm{P}(\mathrm{z}, \mathrm{t})$ on exposed façade and suction $\mathrm{S}(\mathrm{z}, \mathrm{t})$ on the opposite façade of the building. Regarding the variation of wind action along the height $\mathrm{z}$ of the structure, analysed structures encompasses two height zones (EN 1991-1-1, 2005), (CR 1-1-4, 2012): a height z up to $30.0 \mathrm{~m}$ (the length of the structure) and an upper height from $30.0 \mathrm{~m}$ to $43.60 \mathrm{~m}$ (the total height of the structure).
Regarding the computation of wind lateral forces, the passage from speedo-grams to forces observes the code provided stochastic rule (CR 1-1-4, 2012) of velocity composition: instant velocity $\mathrm{V}(\mathrm{z}, \mathrm{t})$ is the result of summing up the mean velocity $\mathrm{V}_{\mathrm{m}}(\mathrm{z})$ and the background fluctuating component $\mathrm{v}(\mathrm{z}, \mathrm{t})$ associated to corresponding height $\mathrm{z}$ of the structure.

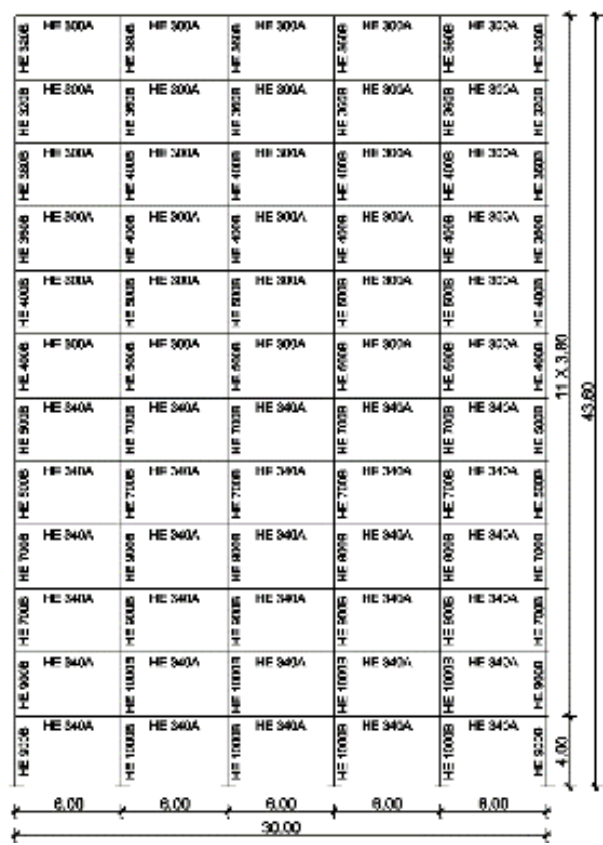

Figure 3. Reference structure

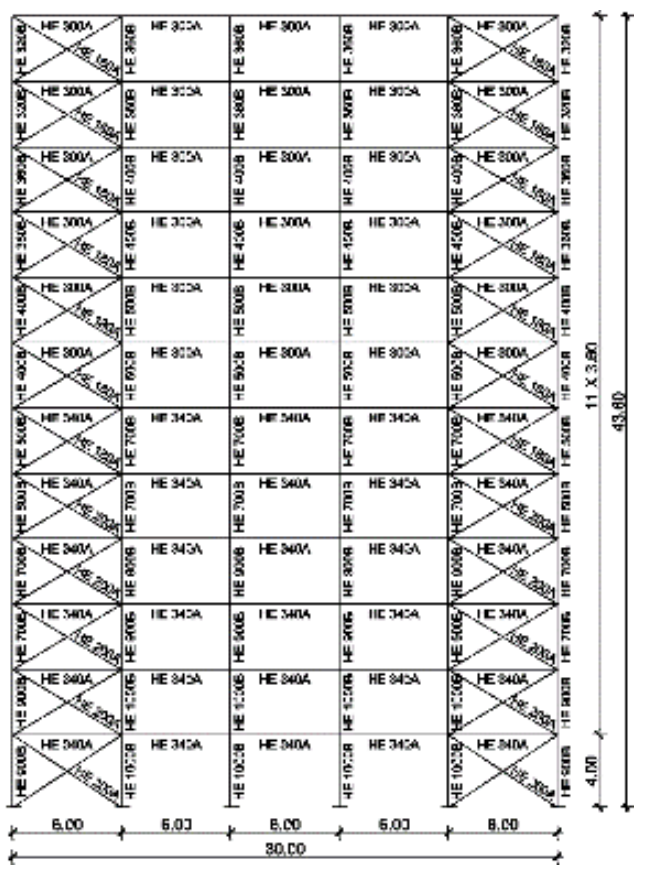

Figure 4. Braced structure

Computation of laterally applied floor level forces $\mathrm{F}(\mathrm{z}, \mathrm{t})$ followed the traditional methodology from velocity to pressure and, further to concentrated values taking into account the pressure coefficient and roughness factor as in the case of computation equivalent static wind loads procedure (ESWL). 
Since computed lateral loads $\mathrm{F}(\mathrm{z}, \mathrm{t})$ are dynamically applied, no gust loading factor has been considered.

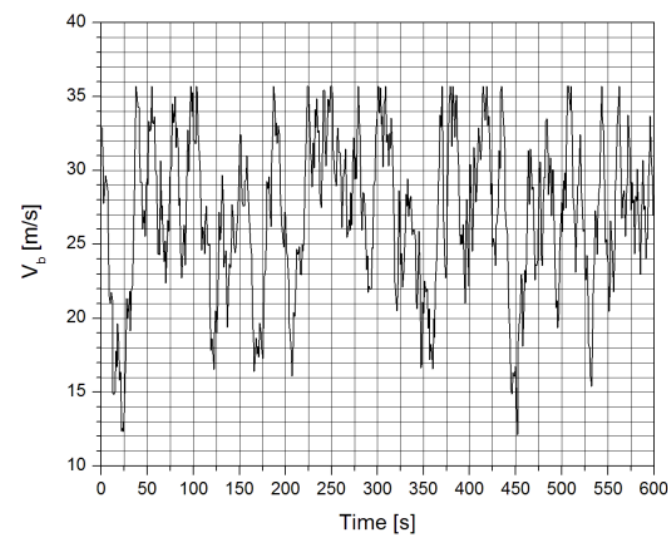

Figure 5. V1 speedo-gram

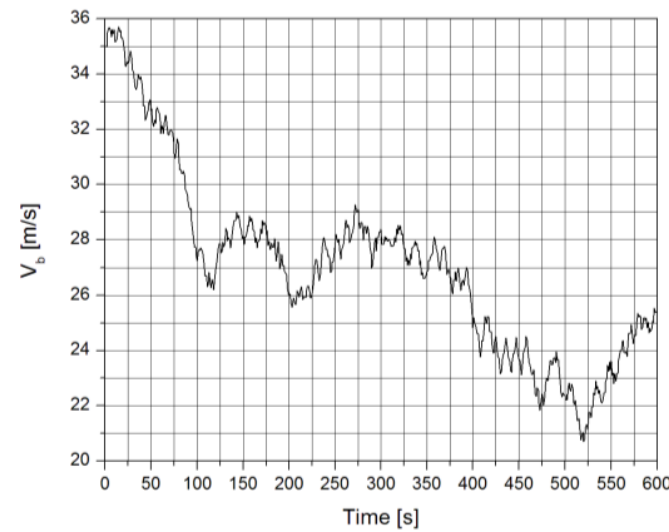

Figure 6. V2 speedo-gram

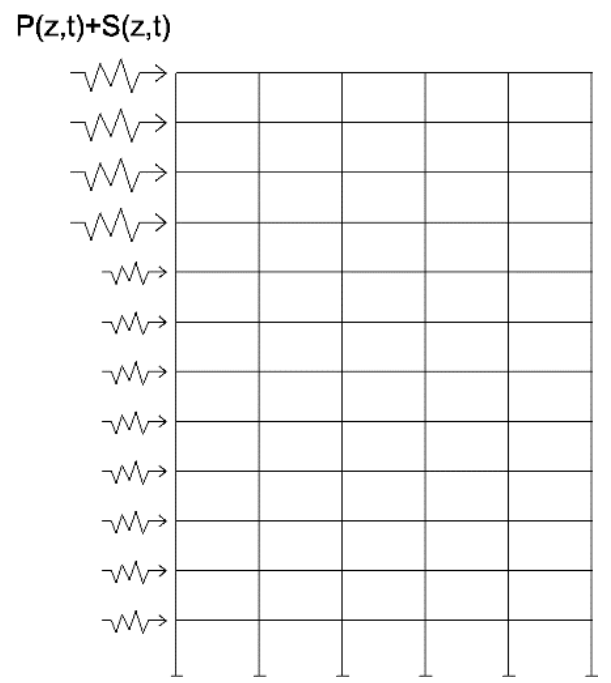

Figure 7. Wind floor forces

\section{METHODOLOGY}

The methodology consists of time history structural analyses associated to elastic behaviour of structures. The analyses are conducted on traditional MDOF dynamic system, Figure 8. Vector $\mathbf{u}(\mathrm{t})$ of the $\mathrm{n}$ degrees of freedom are the floor lateral displacements of the dynamic model. Lumped masses $m_{i}$ are collected in the inertia nxn matrix $\mathbf{M}$.

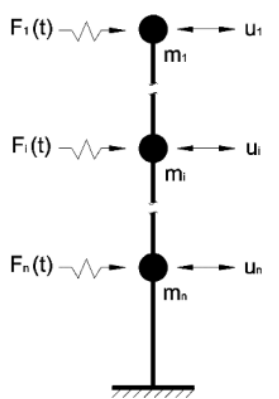

Figure 8. MDOF dynamic system

The associated matriceal differential equation of vibratory state of the dynamic system reads (Chopra, 2017), (Wilson, 2002):

$$
\mathbf{M} \cdot \ddot{\mathbf{u}}(\mathrm{t})+\mathbf{C} \cdot \dot{\mathbf{u}}(\mathrm{t})+\mathbf{R} \cdot \mathbf{u}(\mathrm{t})=\mathbf{F}(\mathrm{t})
$$

where $\dot{\boldsymbol{u}}(t)$ is the velocity n-vector, $\ddot{\boldsymbol{u}}(t)$ is the acceleration nvector, $\boldsymbol{M}$ is the inertia diagonal nxn matrix, $\boldsymbol{C}$ is the Rayleigh type damping nxn matrix and $\boldsymbol{R}$ is the nxn stiffness matrix. The two n-vectors $\mathbf{u}$ and $\mathbf{F}$ are entirely associated to each other. Referring to damping matrix $\boldsymbol{C}$, a viscous critical inherent damping ratio of $2 \%$ has been considered. The matriceal differential equation (1) is dealt with by classical modal analysis (Chopra, 2017), (Wilson, 2002), via usual coordinate transformation:

$$
\mathbf{u}(\mathrm{t})=\boldsymbol{\phi} \cdot \mathbf{x}(\mathrm{t})
$$

where $\boldsymbol{\phi}$ is the nxn modal matrix

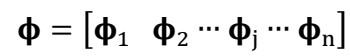

and $\mathbf{x}(t)$ is the $n$-vector collecting the modal coordinates $x_{j}(t)(j=$ $\overline{1, \mathrm{n}})$. It yields

$$
\begin{aligned}
& \dot{\mathbf{u}}(\mathrm{t})=\boldsymbol{\phi} \cdot \dot{\mathbf{x}}(\mathrm{t}) \\
& \ddot{\mathbf{u}}(\mathrm{t})=\boldsymbol{\phi} \cdot \ddot{\mathbf{x}}(\mathrm{t})
\end{aligned}
$$

Substituting (2), (3), (4) into (1), and pre-multiplying by $\boldsymbol{\phi}_{j}{ }^{\mathrm{T}}$, equation (1) becomes:

$$
\begin{gathered}
\mathbf{M} \cdot \boldsymbol{\phi} \cdot \ddot{\mathbf{x}}(\mathrm{t})+\mathbf{C} \cdot \boldsymbol{\phi} \cdot \dot{\mathbf{x}}+\mathbf{R} \cdot \boldsymbol{\phi} \cdot \mathbf{x}(\mathrm{t})=\mathbf{F}(\mathrm{t}) \mid \boldsymbol{\phi}_{j}{ }^{\mathrm{T}} . \\
\boldsymbol{\phi}_{j}{ }^{\mathrm{T}} \cdot \mathbf{M} \cdot \boldsymbol{\phi} \cdot \ddot{\mathbf{x}}(\mathrm{t})+\boldsymbol{\phi}_{j}{ }^{\mathrm{T}} \cdot \mathbf{C} \cdot \boldsymbol{\phi} \cdot \dot{\mathbf{x}}+\boldsymbol{\phi}_{j}{ }^{\mathrm{T}} \cdot \mathbf{R} \cdot \boldsymbol{\phi} \\
\cdot \mathbf{x}(\mathrm{t})=\boldsymbol{\phi}_{j}{ }^{\mathrm{T}} \cdot \mathbf{F}(\mathrm{t})
\end{gathered}
$$

Orthogonality expressions of eigen vectors with respect inertia matrix $\mathbf{M}$ and stiffness matrix $\mathbf{R}$ read:

$$
\boldsymbol{\phi}_{\mathrm{j}}^{\mathrm{T}} \cdot \mathbf{M} \cdot \boldsymbol{\phi}_{\mathrm{k}}=0(\mathrm{j}, \mathrm{k}=\overline{1, \mathrm{n}} ; \mathrm{j} \neq \mathrm{k})
$$




$$
\boldsymbol{\phi}_{\mathrm{j}}^{\mathrm{T}} \cdot \mathbf{R} \cdot \boldsymbol{\phi}_{\mathrm{k}}=0(\mathrm{j}, \mathrm{k}=\overline{1, \mathrm{n}} ; \mathrm{j} \neq \mathrm{k})
$$

Orthogonality of eigen vectors is, also, imposed with respect linear viscous damping matrix C (Ladar, 2013), (Chopra, 2017):

$$
\boldsymbol{\phi}_{\mathrm{j}}^{\mathrm{T}} \cdot \mathbf{C} \cdot \boldsymbol{\phi}_{\mathrm{k}}=0(\mathrm{j}, \mathrm{k}=\overline{1, \mathrm{n}} ; \mathrm{j} \neq \mathrm{k})
$$

Finally, equation (1) reads

$$
M_{\mathrm{j}} \cdot \ddot{x}_{j}(\mathrm{t})+C_{\mathrm{j}} \cdot \dot{x}_{j}(\mathrm{t})+R_{\mathrm{j}} \cdot \mathrm{x}_{j}(\mathrm{t})=F_{\mathrm{j}}(\mathrm{t})
$$

where modal mass $M_{\mathrm{j}}$, modal damping $C_{\mathrm{j}}$, modal stiffness $R_{\mathrm{j}}$ and modal forces $F_{\mathrm{j}}$ are given by:

$$
\begin{gathered}
M_{\mathrm{j}}=\boldsymbol{\phi}_{\mathrm{j}}^{\mathrm{T}} \cdot \mathbf{M} \cdot \boldsymbol{\phi}_{\mathrm{j}} \\
C_{\mathrm{j}}=\boldsymbol{\phi}_{\mathrm{j}}^{\mathrm{T}} \cdot \mathbf{C} \cdot \boldsymbol{\phi}_{\mathrm{j}} \\
R_{\mathrm{j}}=\boldsymbol{\phi}_{\mathrm{j}}^{\mathrm{T}} \cdot \mathbf{R} \cdot \boldsymbol{\phi}_{\mathrm{j}} \\
F_{\mathrm{j}}=\boldsymbol{\phi}_{\mathrm{j}}^{\mathrm{T}} \cdot \mathbf{F} \cdot \boldsymbol{\phi}_{\mathrm{j}}
\end{gathered}
$$

Integration of the $\mathrm{n}$ differential equations (5) leads to the solution $x_{j}(t)$ expressed by convolution integral (Chopra, 2017)

$$
x_{j}(t)=\frac{F_{\mathrm{j}}}{M_{\mathrm{j}} \cdot \omega_{j}^{2}} \cdot \omega_{j} \cdot \int_{0}^{t} f(\tau) \cdot \sin \omega_{j} \cdot(t-\tau) \cdot d \tau
$$

Integration of homogeneous form of (1) leads to parameters associated to eigen problem: eigen periods $T_{j}$ and eigen circular frequencies $\omega_{j}$. Back substitution of (2) leads to the solution in $\mathbf{u}(\mathrm{t})$ in terms of structural parameters and applied dynamic forces. Entire wind response is expressed in lateral floor displacements $u_{i}(t)$, base shear force $\mathrm{F}_{\mathrm{b}}(\mathrm{t})$, wind induced energy $\mathrm{E}_{\mathrm{i}}$ and modal damping energy $E_{\mathrm{d}}$.

\section{NUMERICAL RESULTS}

Modal analysis of the two structures yields into following numerical values of the parameters associated to the first six natural modes of vibration, Table 9, Table 10.

\begin{tabular}{|c|c|c|c|c|c|c|}
\hline $\mathrm{j}$ & 1 & 2 & 3 & 4 & 5 & 6 \\
\hline $\mathrm{T}_{\mathrm{j}}[\mathrm{s}]$ & 3.24 & 1.13 & 0.62 & 0.40 & 0.28 & 0.22 \\
\hline$\omega_{\mathrm{j}}[\mathrm{rad} / \mathrm{s}]$ & 1.93 & 5.53 & 10.06 & 15.54 & 21.88 & 27.95 \\
\hline
\end{tabular}

Table 9. Reference structure

\begin{tabular}{|c|c|c|c|c|c|c|}
\hline $\mathrm{j}$ & 1 & 2 & 3 & 4 & 5 & 6 \\
\hline $\mathrm{T}_{\mathrm{j}}[\mathrm{s}]$ & 1.66 & 0.47 & 0.24 & 0.22 & 0.209 & 0.200 \\
\hline$\omega_{\mathrm{j}}[\mathrm{rad} / \mathrm{s}]$ & 3.76 & 13.21 & 26.05 & 28.36 & 29.97 & 31.28 \\
\hline
\end{tabular}

Table 10. Braced structure

A visible association between above parameters and increased stiffness of braced structure may be concluded. Regarding the structural response to wind actions in terms of lateral floor displacements of the top floor, their time-variations are given in Figure 11 to Figure 14. Base shear force induced by wind is the next parameter of the structural response. While the base shear force is deeply influenced by the wind type action, Figure 15 to Figure 18, it is also dependent on lateral stiffness of acted upon structure. A comparative picture of the dependency of base shear force, associated to a 30 seconds time interval of each wind action, on wind type and lateral stiffness is presented in Figure 19 and Figure 20.

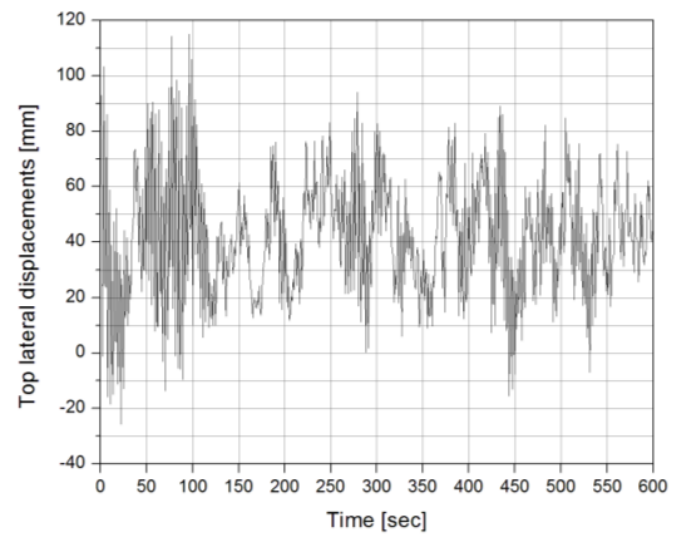

Figure 11. Reference structure-top lateral displacements-V1

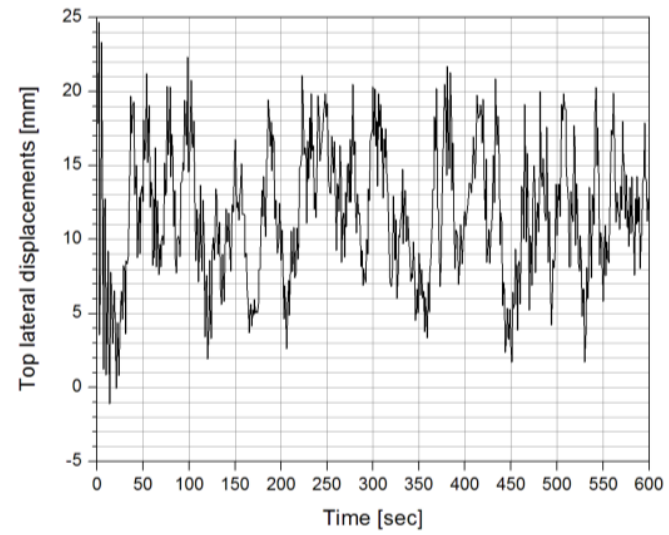

Figure 12. Braced structure-top lateral displacements-V1

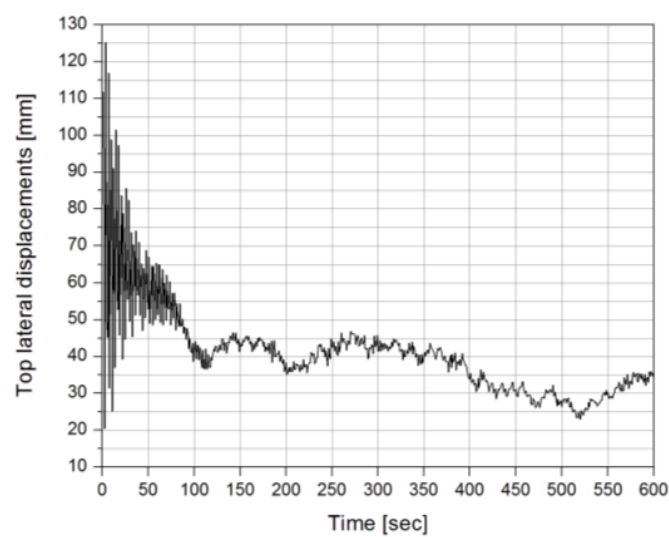

Figure 13. Reference structure-top lateral displacements-V2

Mechanical state of multistory structure acted upon by lateral forces cannot be entirely expressed without a reference to its energy state. Its scalar nature and its complex structure (that includes stiffness state, inertia state, damping state, static and kinematic parameters), energy state is more comprehensive than the more traditional static and kinematic states. Energy state may be expressed in several energy components: induced energy, 
dissipated energy by (inherent and / or added) damping, kinetic energy and potential (deformation) energy.

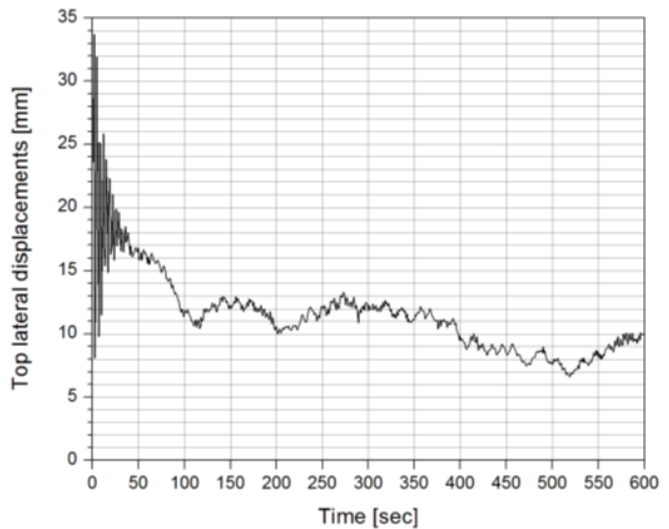

Figure 14. Braced structure-top lateral displacements-V2

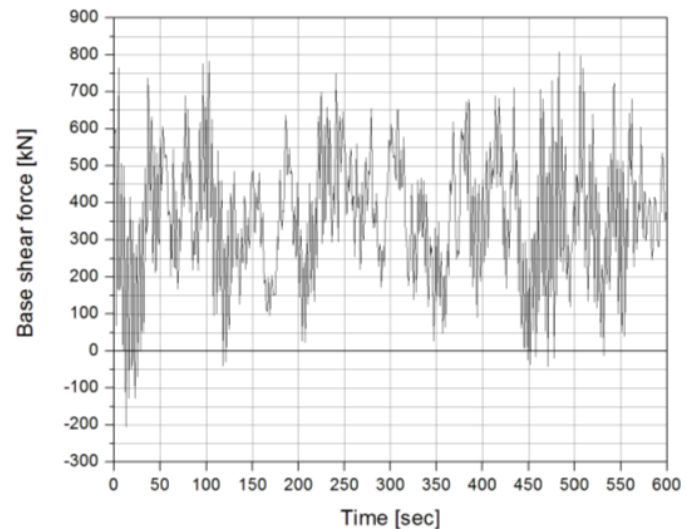

Figure 15. Reference structure-base shear force-V1

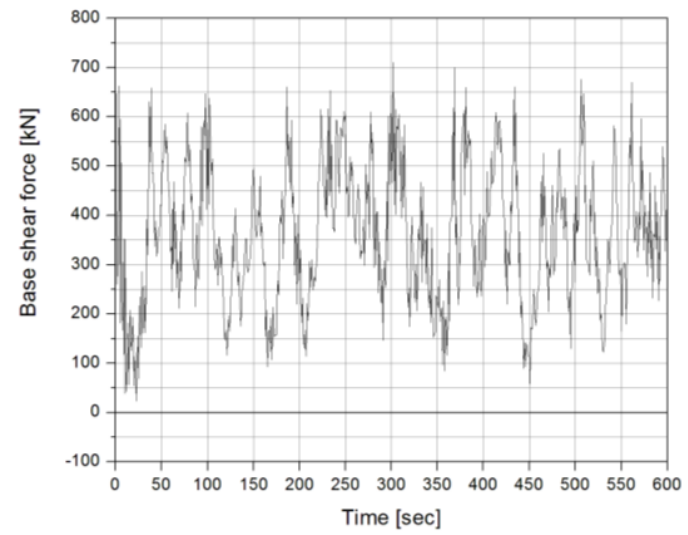

Figure 16. Braced structure-base shear force-V1

Present contribution deals with the energy state of the analyzed structures expressed by input energy $\mathrm{E}_{\mathrm{i}}$, Figure 21, Figure 22. While the reduction in lateral floor displacements is still a common and direct objective of structural design under dynamic actions, the effect of lateral stiffness will stay as an effective means to it. No co-lateral effects will be noticed if the energy state is not emphasized. Input energy is the engine that starts the vibratory state of the structure and, therefore, the input energy has to be "cut off' if this state has to be reduced. In other words, the induced energy should be allotted an input state rather than being regarded as an output effect. Induced energy by wind action is what can be reduced by structural design and protection to wind action (as in the case of seismic passive protection - a more popular subject).

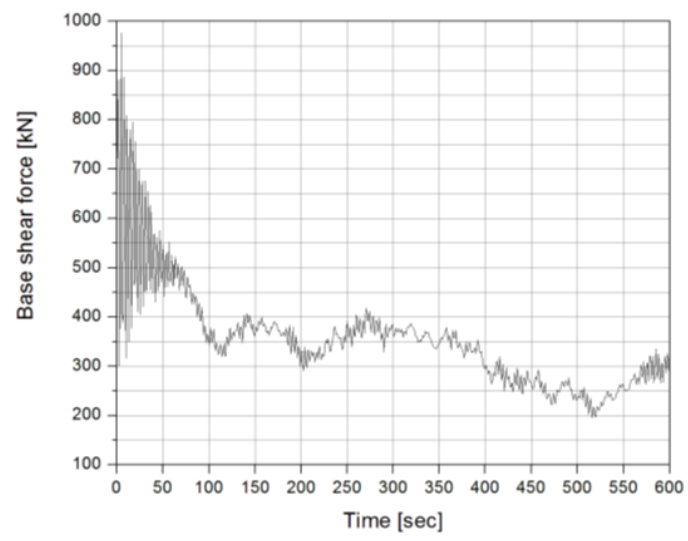

Figure 17. Reference structure-base shear force-V2

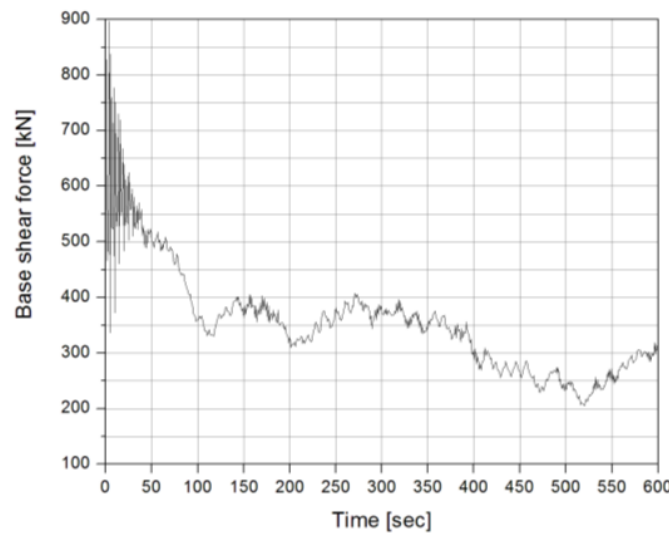

Figure 18. Braced structure-base shear force-V2

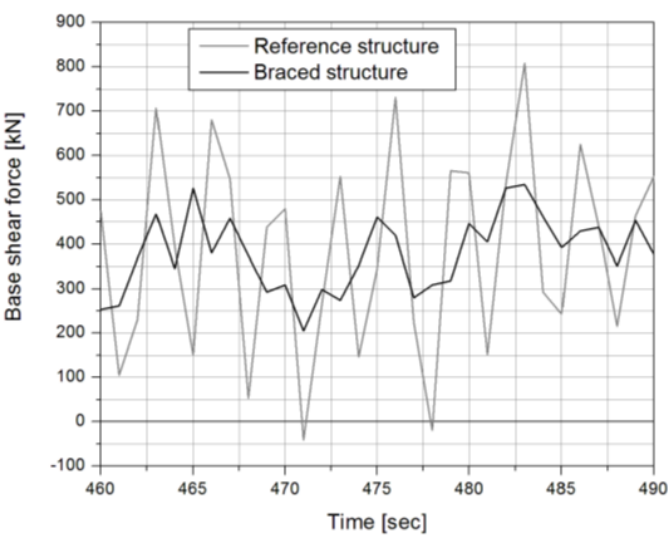

Figure 19. Base shear force-V1. Reference vs braced structure

Energy state of a structure dynamically acted upon is not a new approach in structural design. In the case of seismic action, energy state has been largely developed and referred to (Ladar, 2013), (Uang, 1990). Time variation of induced energy in the case of the analysed structures and the two wind actions, Figure 21 , Figure 22, shows a clear dependency on the energy state on the lateral stiffness and on the type of wind action. 


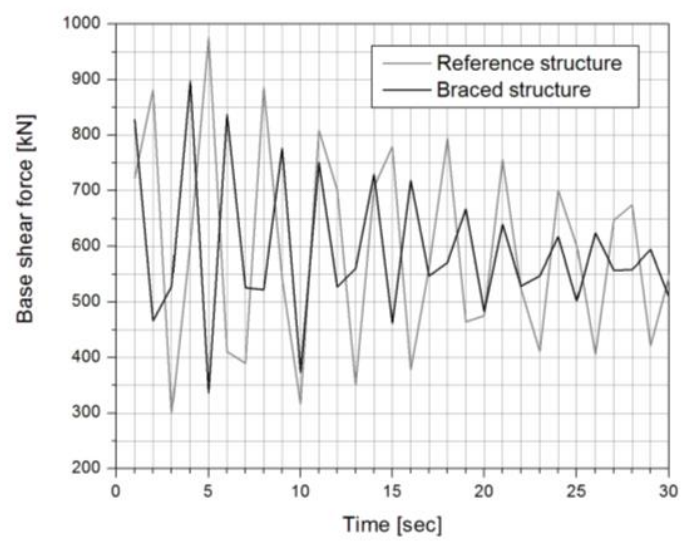

Figure 20. Base shear force-V2. Reference vs braced structure

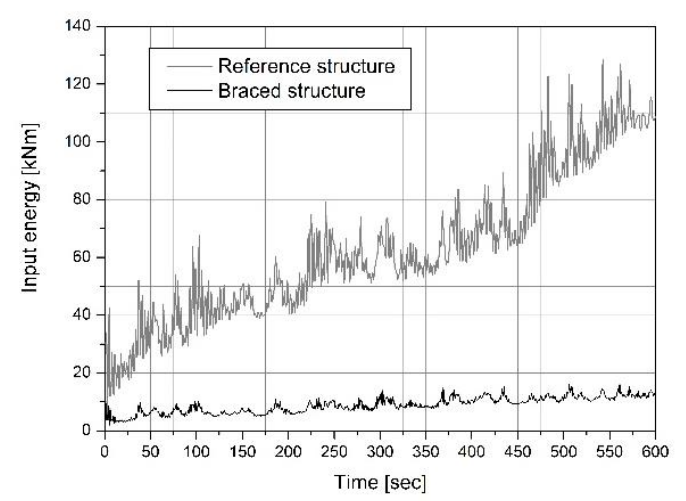

Figure 21. Input energy $E_{i}-V 1$. Reference vs braced structure

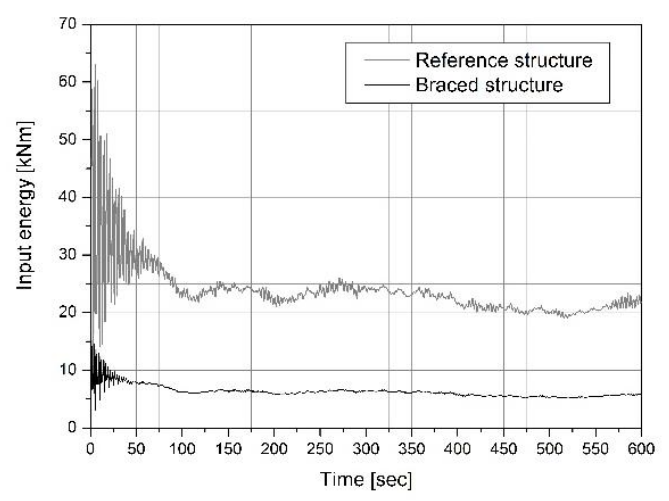

Figure 22. Input energy $E_{i}-V 2$. Reference vs braced structure

\section{CONCLUDING REMARKS}

Mechanical state of multistory structures acted upon by wind has been analyzed in its traditional forms made up of static and kinematic parameters. Induced input energy state has been proposed as a new component of the classical mechanical state. Analyzed structures, wind actions and computed numerical parameters have been selected aiming at their representativeness from the point of view of the structural response to wind action. The structures are analyzed in their two different states: a flexible unbraced state and a rigid braced state. The two wind actions V1 and $\mathrm{V} 2$ are, in their turn, very different regarding their variation in time: while V1 is steadily variable, wind V2 is continuously descending within a narrow distribution. Regarding the structural response, the reduced set of classical static and kinematic parameters reflect by their values and time variation these input state. Proposed energy state - as a new component of the traditional mechanical state - is expressed, here, through its input energy $E_{i}$ component. The selection of computed parameters of the structural response to wind action aims at proving that energy state is a versatile tool in expressing the dynamic behavior of multistory structures. Indeed, the energy states associated to both lateral stiffness cases and to both wind actions are closely specific in their values and time variation. The possibility of expressing dynamic response to wind action in energy terms has to be regarded as the objective of present contribution, rather than the numerical values of computed parameters.

\subsection{References}

Barszcz, T., Marzena B., Andrzej B., Mateusz W., 2012. Wind speed modeling using Weierstrass function fitted by a genetic algorithm. Journal of Wind Engineering and Industrial Aerodynamics, 109, pp. 68-78.

Blaga, F., Alexa P., 2016. Statics and kinematics in structural dynamic response to wind action. SDSS 2016, pp. 59-65.

Chen, X., Ahsan K., 2005. Evaluation of equivalent static wind loads on buildings. Proc., 10th int. conf. on wind eng.(CD-Rom).

Chopra, A. K., 2007. Dynamics of Structures, 3rd Edition.Prentice Hall International.

CR0, 2012. Design Code. Basis of structural design (in Romanian).

CR 1-1-4, 2012. Design code. Assessment of wind action on structures (in Romanian).

Davenport, A. G., 1967. Gust loading factors. Journal of the Structural Division, 93(3), pp. 11-34.

Davenport, A. G., 1995. How can we simplify and generalize wind loads. J. Wind Eng. Ind. Aerodyn., 58, pp. 139-141.

EN 1991-1-4, 2005. Eurocode 1: Actions on structures-Part 1-4: General actions, Wind actions". CEN, Brussels.

Holmes, J. D., 2002. Effective static load distributions in wind engineering. J. Wind Eng. Ind. Aerodyn., 90, pp. 91-109.

Holmes, J. D., 2012. Modern techniques for effective wind load distributions on large roofs. ACEM', 12.

Holmes, J.D., 2015. Wind Loading of Structures. Third Edition. CRC Press.

Kasperski, M., 1992. Extreme wind load distributions for linear and nonlinear design. Eng. Struc., 14 (1), pp. 27-34.

Ladar, I., 2013. Seismic response of steel multi-story structures. An energy approach. $\mathrm{PhD}$ Thesis, Technical University of Cluj - Napoca, (in Romanian).

Piccardo, G., Solari G., 2000. 3-D wind-excited response of slender structures: Closed form solution. ASCE, 126, pp. 936943. 
Piccardo, G., Solari G., 2002. 3-D gust effect factor for slender vertical structures, Prob. Eng. Mech., 17, pp. 143-155.

Puthanpurayil, A., Rajesh P. D., Athol J. C., 2011. Modelling of In-Structure Damping: A Review of the State-of-the-art. Proc. Ninth Pacific Conf. Earthquake Engineering, [Online]. Paper, no. 091.

Simiu, E., 1976. Equivalent static wind loads for tall buildings design. Journal of the Structural Division, 102(4), pp. 719-737.

Simiu, E., Scanlan H.R., 1996. Wind effects on structures. Fundamentals and Applications to Design, 3rd Edition. John Wiley \& Sons.

Solari, G., 1982. Alongwind response estimation: closed form solution. Journal of the Structural Division, 108(1), pp. 225-244.

Tamura, Y., Katsumura A., 2012. Universal equivalent static wind load for structures. The Seventh International Colloquium on Bluff Body Aerodynamics and Applications (BNAA7), pp. 26.

Uang, C. M., Bertero V. V., 1990. Evaluation of seismic energy in structures. Earthquake Engineering and Structural Dynamics, 19(1), pp. 77-90.

Wilson, E. L., 2002. Three - Dimensional Static and Dynamic Analysis of Structures. A Physical Approach With Emphasis on Earthquake Engineering. Computers and Structures, Inc. Berkeley, California, USA Third Edition Reprint. 